\title{
Quality of life in patients rehabilitated with implant-supported prostheses
}

\author{
Anderson Nicolly Fernandes-Costa ${ }^{1}$, Micaella \\ Pollyana Silva do Nascimento Costa2 ${ }^{2}$, Tâmara Cabral \\ Rodrigues $^{3}$, Karyna de Melo Menezes ${ }^{4}$, Patrícia dos \\ Santos Calderon ${ }^{5}$, Bruno César de Vasconcelos Gurgel ${ }^{6}$
}

\author{
'MSc in Public Health, DDS, \\ Universidade Federal do Rio Grande \\ do Norte. Natal/RN, Brazil. \\ ${ }^{2}$ DDS, Universidade Federal do Rio \\ Grande do Norte. Natal/RN, Brazil. \\ ${ }^{3}$ DDS, Universidade Federal do Rio \\ Grande do Norte. Natal/RN, Brazil. \\ ${ }^{4} \mathrm{MSc}$ in Public Health, DDS, \\ Universidade Federal do Rio Grande \\ do Norte. Natal/RN, Brazil. \\ ${ }^{5}$ Associate Professor, $\mathrm{PhD}$ \\ DDS, Department of Dentistry. \\ Universidade Federal do Rio Grande \\ do Norte. Natal/RN, Brazil. \\ ${ }^{6}$ Associate Professor, PhD, \\ DDS, Department of Dentistry. \\ Universidade Federal do Rio Grande \\ do Norte. Natal/RN, Brazil. \\ Corresponding author: \\ MSc Anderson Nicolly \\ Fernandes-Costa \\ Senador Salgado Filho Ave., 1787, \\ Lagoa Nova, Natal/RN, Brazil \\ Zip Code: $59056-000$ \\ Phone: +55 84 98716-6865 \\ E-mail: anson.fernandes@hotmail.com \\ Received: July 26, 2017 \\ Accepted: September 14, 2017
}

Aim: To evaluate the impact of rehabilitation with implantsupported prostheses on the quality of life (QoL) of patients. Methods: The OHIP-14 questionnaire was applied to 114 patients and information regarding gender, age, type of prosthesis and time of use were obtained. To analyze whether there were any statistically significant differences between the mean scores of the seven parameters of the OHIP-14, the Mann-Whitney and Kruskal-Wallis test were used. All data were evaluated using a significance level of $5 \%$. Results: Patients were predominantly female $(78.9 \%)$ and single crowns users (41.2\%). Patients reported a good QoL (3.07). Psychological discomfort and physical pain were the worst dimensions evaluated by the subjects. Results differed significantly $(p<0.05)$ only for functional limitations and psychological discomfort in the different genders. Conclusions: Patients presented a high level of quality of life, regardless of age, duration of use and the type of prosthesis used. However, women presented more psychological distress and functional limitations than men.

Keywords: Quality of life. Dental prostheses, implantsupported. Patient satisfaction. Mouth rehabilitation. 


\section{Introduction}

Therapy with implant-supported prostheses implants has been largely studied for the oral rehabilitation of edentulous patients ${ }^{1}$. Due to the limitations of conventional prosthesis treatments, implant-supported prostheses (single crowns; bridges; complete dentures: fixed or removable) can be planned to improve stability, retention, masticatory function and phonetics in patients. Furthermore, these approaches also improve the physical, psychological and social well-being of the patient ${ }^{2}$ and are considered the gold standard for the treatment of edentulism ${ }^{3}$.

However, all these benefits can become meaningless if what the patient considers important for his/her satisfaction with treatment is different to that of the dentist. Do not considering patients' expectations on the part of professionals can contribute to oral rehabilitation failure and produce typical psychosocial responses, such as anxiety, insecurity, low self-esteem and introversion ${ }^{4}$. During the initial planning of treatment, it is necessary to understand the patient's expectations, since the subject's perception of his/her oral health is related to his/her quality of life (QoL) ${ }^{5}$.

Due to its subjectivity, complexity and individual perception, it is difficult to evaluate QoL. According to the World Health Organization (WHO), QoL is the perception, on the part of individuals or groups, regarding the satisfaction of their own needs and what is not denied in propitious for their happiness ${ }^{6}$. Besides that, the WHO emphasizes the importance of oral health-related QoL to use in its campaigns not only images portraying pain-free life but also aesthetic images with beautiful smiles as an image of complete well-being ${ }^{7}$.

Traditionally, the surveys are concerned with treatment efficacy involving clinical parameters rather than individual patient perspective. In contrast, as a result of this difference, recent research is refocused to consider how oral health affects far reaching aspects of life such as psychosocial interaction, self-esteem, intimacy, overall health, and performance at work ${ }^{8}$.

When QoL is evaluated in relation to oral health, modifications in oral health have been found to negatively interfere in an individual's QoL and this can also be affected by the satisfaction or dissatisfaction with an oral condition ${ }^{9}$. Mcgrath and Bedi ${ }^{10}$ have shown that problems experienced by patients who have lost teeth were both functional and psychosocial and were mainly associated with negative feelings. Therefore, rehabilitation with implant-supported prostheses provides a positive effect on the QoL associated with oral health and has a strong social, psychological and emotional impact on the daily life of each patient ${ }^{11}$.

Several instruments have been developed with the aim of evaluating and quantifying QoL. The Oral Health Impact Profile (OHIP) is one of these instruments; its simplified form (OHIP-14) was developed by Slade and Spencer ${ }^{12}$, derived from the original version (OHIP-49) also developed by Slade and Spencer ${ }^{12}$. Even in its abbreviated form, this questionnaire is reliable and valid in several languages ${ }^{13}$ and is considered a good index for evaluating QoL, becoming a methodology of choice for such studies ${ }^{5,11}$.

As OHIP-14 is easy and quick to apply, it is possible to verify the effectiveness of oral rehabilitation with implant-supported prostheses, evaluating the physical and emo- 
tional state of the patient, their future limitations, level of performance in their daily life, degree of satisfaction of their needs and the impact on their QoL. Therefore, the aim of this study was to evaluate the impact of oral rehabilitation with prostheses supported or retained by implants on patients' QoL.

\section{Materials and Methods}

\section{Sample}

This cross-sectional study was performed in patients with implant-supported prostheses treated at the Department of Dentistry of the Federal University of Rio Grande do Norte (UFRN) during the period from 2000 to 2010. This search was approved by the Ethics Committee of the UFRN (protocol: 349.152/2013) and it has been conducted in full accordance with the World Medical Association Declaration of Helsinki. All patients who agreed to participate of this search assigned a written consent. Patients who have prosthesis less than six months in function were excluded from the sample. The calculation of the sample size was based on the mean observed in our study for general OHIP-14. A formula for finite sample populations was used to calculate the sample of this study with a significance of $5 \%$ and power test of $80 \%$. With an finite population of 155 individuals, the sample of patients required for OHIP-14 application was 109 individuals.

\section{Data Collect}

After the selection of patients, the OHIP-14 was applied by previously trained researchers and information about gender, age, type of prosthesis and time of use of prosthesis were obtained from the patient's medical records. In cases of patients that used more than one type of prosthesis, the type of prostheses with the highest number of implants was considered. All patients were informed about the OHIP-14 methodology and the interviewer was always available for providing help.

The OHIP-14 consists of 14 items subdivided into seven parameters (functional limitation, physical pain, psychological discomfort, physical incapacity, psychological incapacity, social disability and handicap). For these items, participants were asked to evaluate how often they felt and experienced an impact on oral health after rehabilitation treatment be concluded using a Likert scale of five points coded 0 ("never"), 1 ("rarely"), 2 ("sometimes"), 3 ("frequently"), and 4 ("always").

The calculation of the impact of the prosthesis on the patient's QoL was performed by a standard method of calculation of OHIP-14, using the specific weight for each question². Finally, when all punctuation from each question was added, a final score was obtained, and the higher submitted score, the greater the negative impact on QoL for the individual ${ }^{14}$.

\section{Statistical Analysis}

For the statistical analysis of parameters in relation to gender, the Mann-Whitney test was used. The Kruskal-Wallis test was utilized for the variables; age, type of prostheses and time of use of prosthesis. For statistical purposes, all variables were cate- 
gorized. The OHIP-14 variable and its dimensions were categorized as "impact" on QoL $(>0)$ and "no impact" on QoL $(=0)$. The impact of a parameter on QoL indicates a negative effect of the rehabilitation The individual's age was categorized according to the age, as adult ( $<60$ years) or elderly ( $\geq 60$ years). The type of prosthesis was categorized as single crowns, overdentures and multiple partial prostheses or total prostheses (fixed). For the time of use of the prostheses, categorization was performed in individuals who had used them for up to six years or for more than six years.

\section{Results}

The OHIP-14 was applied in 114 patients during the period of May/2013 to May/2014. A higher proportion of females (78.9\%) and individuals who used single prostheses (41.2\%) were observed. According to gender, between men there was higher prevalence of multiple partial prostheses or total prostheses (44\%) and between women the most prevalent was single prostheses (43.8\%). The sample had a mean age of 55.46 years $( \pm 12.91)$ with a variation from 18 to 84 years. Furthermore, the majority of the patients presented prostheses with more than six years of mean time of use.

Results demonstrate that the patients evaluated have a high QoL, as the value of the general OHIP-14 was close to zero (3.07), with a variation from 0 to 56 . However, it can be seen that the dimensions of psychological discomfort and physical pain presented the highest means, even though these parameters demonstrated low values (Fig. 1).

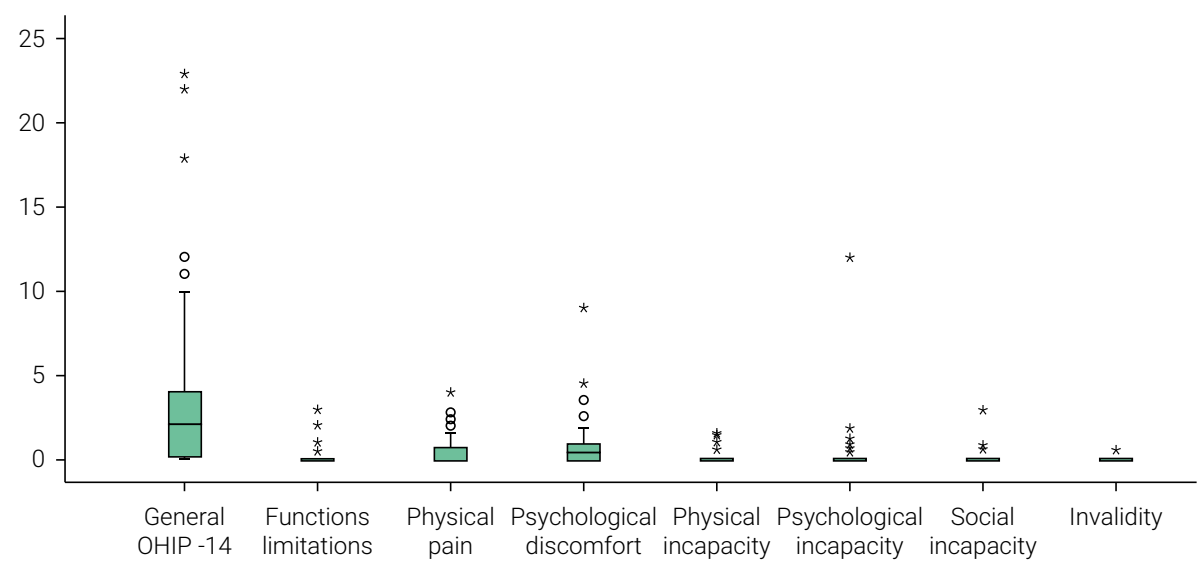

Caption: Circles and stars are respectively outliers and extreme outliers.

Figure 1. Box-plot distribution of OHIP-14 and its dimensions.

The distribution of the analysis of the OHIP-14 or the parameters of gender, age, type of prosthesis and time of use of prosthesis demonstrated significantly statistical differences $(p<0.05)$ just for gender, with regard to functional limitations and psychological discomfort, which presented the worst QoL scores (Tables 1 and 2). 
Table 1. Distribution of oral health impact on QoL, as evaluated by the OHIP-14, and parameters according to gender and age.

\begin{tabular}{|c|c|c|c|c|c|c|}
\hline & \multicolumn{2}{|c|}{ Gender } & \multirow[b]{2}{*}{$\mathrm{p}$} & \multicolumn{2}{|c|}{ Age } & \multirow[b]{2}{*}{$\mathrm{p}$} \\
\hline & $\begin{array}{l}\text { Male } \\
\mathrm{n}(\%)\end{array}$ & $\begin{array}{c}\text { Female } \\
\mathrm{n}(\%)\end{array}$ & & $\begin{array}{l}\text { Adult } \\
\mathrm{n}(\%)\end{array}$ & $\begin{array}{c}\text { Elderly } \\
\mathrm{n}(\%)\end{array}$ & \\
\hline \multicolumn{7}{|c|}{ General OHIP-14 } \\
\hline No impact & $10(40.0)$ & $23(25.8)$ & \multirow{2}{*}{0.259} & $21(32.3)$ & $12(24.5)$ & \multirow{2}{*}{0.482} \\
\hline Impact & $15(60.0)$ & $66(74.2)$ & & $44(67.7)$ & $37(75.5)$ & \\
\hline \multicolumn{7}{|c|}{ Functional limitations } \\
\hline No impact & $25(100.0)$ & $75(84.3)$ & \multirow{2}{*}{0.037} & $56(86.2)$ & $44(89.8)$ & \multirow{2}{*}{0.765} \\
\hline Impact & - & $14(15.7)$ & & $9(13.8)$ & $5(10.2)$ & \\
\hline \multicolumn{7}{|l|}{ Physical pain } \\
\hline No impact & $12(48.0)$ & $52(58.4)$ & \multirow{2}{*}{0.484} & $41(63.1)$ & $23(46.9)$ & \multirow{2}{*}{0.126} \\
\hline Impact & $13(52.0)$ & $37(41.6)$ & & $24(36.9)$ & $26(53.1)$ & \\
\hline \multicolumn{7}{|c|}{ Psychological discomfort } \\
\hline No impact & $18(72.0)$ & $38(42.7)$ & \multirow{2}{*}{0.018} & $33(50.8)$ & $23(46.9)$ & \multirow{2}{*}{0.829} \\
\hline Impact & $7(28.0)$ & $51(57.3)$ & & $32(49.2)$ & $26(53.1)$ & \\
\hline \multicolumn{7}{|c|}{ Physical incapacity } \\
\hline No impact & $23(92.0)$ & $75(84.3)$ & \multirow{2}{*}{0.516} & $58(89.2)$ & $40(81.6)$ & \multirow{2}{*}{0.377} \\
\hline Impact & $2(8.0)$ & $14(15.7)$ & & $7(10.8)$ & $9(18.4)$ & \\
\hline \multicolumn{7}{|c|}{ Psychological incapacity } \\
\hline No impact & $24(96.0)$ & $76(85.4)$ & \multirow{2}{*}{0.298} & $55(84.6)$ & $45(91.8)$ & \multirow{2}{*}{0.382} \\
\hline Impact & $1(4.0)$ & $13(14.6)$ & & $10(15.4)$ & $4(8.2)$ & \\
\hline \multicolumn{7}{|c|}{ Social disability } \\
\hline No impact & $24(96.0)$ & 81 (91.0) & \multirow{2}{*}{0.681} & 61 (93.8) & $44(89.8)$ & \multirow{2}{*}{0.495} \\
\hline Impact & $1(4.0)$ & $8(9.0)$ & & $4(6.2)$ & $5(10.2)$ & \\
\hline \multicolumn{7}{|l|}{ Handicap } \\
\hline No impact & $25(100.0)$ & $87(97.8)$ & \multirow{2}{*}{1.000} & 64 (98.5) & $48(98.0)$ & \multirow{2}{*}{1.000} \\
\hline Impact & - & $2(2.2)$ & & $1(1.5)$ & $1(2.0)$ & \\
\hline
\end{tabular}

Table 2. Distribution of the impact of oral health on QoL, as evaluated by OHIP-14, with regard to the type of prosthesis used and time of use of prosthesis.

\begin{tabular}{|c|c|c|c|c|c|c|c|}
\hline & \multicolumn{3}{|c|}{ Type of prosthesis } & \multirow[b]{2}{*}{$\mathrm{p}$} & \multicolumn{2}{|c|}{ Time of use of prosthesis } & \multirow[b]{2}{*}{$\mathrm{p}$} \\
\hline & $\begin{array}{c}\text { Single } \\
\text { prostheses } \\
\mathrm{n}(\%)\end{array}$ & $\begin{array}{l}\text { Overdenture } \\
n(\%)\end{array}$ & $\begin{array}{c}\text { Multiple } \\
\text { partial or total } \\
\text { prostheses } \\
n(\%)\end{array}$ & & $\begin{array}{c}\leq 6 \text { years } \\
n(\%)\end{array}$ & $\begin{array}{c}>6 \text { years } \\
\mathrm{n}(\%)\end{array}$ & \\
\hline \multicolumn{8}{|c|}{ General OHIP-14 } \\
\hline No impact & $14(29.8)$ & $3(13.6)$ & $16(35.6)$ & \multirow{2}{*}{0.176} & $9(24.3)$ & $24(31.2)$ & \multirow{2}{*}{0.593} \\
\hline Impact & $33(70.2)$ & $19(86.4)$ & $29(64.4)$ & & $28(75.7)$ & $53(68.8)$ & \\
\hline \multicolumn{8}{|l|}{$\begin{array}{l}\text { Functional } \\
\text { limitations }\end{array}$} \\
\hline No impact & $40(85.1)$ & $20(90.9)$ & $40(88.9)$ & \multirow{2}{*}{$-a$} & $33(89.2)$ & $67(87.0)$ & \multirow{2}{*}{1.000} \\
\hline Impact & $7(14.9)$ & $2(9.1)$ & $5(11.1)$ & & $4(10.8)$ & $10(13.0)$ & \\
\hline \multicolumn{8}{|l|}{ Physical pain } \\
\hline No impact & $28(59.6)$ & $8(36.4)$ & $28(62.2)$ & \multirow{2}{*}{0.111} & $21(56.8)$ & $43(55.8)$ & \multirow{2}{*}{1.000} \\
\hline Impact & $19(40.4)$ & $14(63.6)$ & $17(37.8)$ & & $16(43.2)$ & $34(44.2)$ & \\
\hline
\end{tabular}




\begin{tabular}{|c|c|c|c|c|c|c|c|}
\hline $\begin{array}{l}\text { Psychological } \\
\text { discomfort }\end{array}$ & & & & & & & \\
\hline No impact & $23(48.9)$ & $8(36.4)$ & $25(55.6)$ & \multirow{2}{*}{0.336} & $16(43.2)$ & 40 (51.9) & \multirow{2}{*}{0.503} \\
\hline Impact & $24(51.1)$ & $14(63.6)$ & $20(44.4)$ & & $21(56.8)$ & $37(48.1)$ & \\
\hline \multicolumn{8}{|l|}{$\begin{array}{l}\text { Physical } \\
\text { incapacity }\end{array}$} \\
\hline No impact & $40(85.1)$ & $17(77.3)$ & $41(91.1)$ & \multirow{2}{*}{ _a } & $31(83.8)$ & $67(87.0)$ & \multirow{2}{*}{0.860} \\
\hline Impact & $7(14.9)$ & $5(22.7)$ & $4(8.9)$ & & $6(16.2)$ & $10(13.0)$ & \\
\hline \multicolumn{8}{|l|}{$\begin{array}{l}\text { Psychological } \\
\text { incapacity }\end{array}$} \\
\hline No impact & $44(93.6)$ & 19 (86.4) & 37 (82.2) & \multirow{2}{*}{$-a$} & $33(89.2)$ & $67(87.0)$ & \multirow{2}{*}{1.000} \\
\hline Impact & $3(6.4)$ & $3(13.6)$ & $8(17.8)$ & & $4(10.8)$ & $10(13.0)$ & \\
\hline \multicolumn{8}{|c|}{ Social disability } \\
\hline No impact & $43(91.5)$ & $22(100.0)$ & 40 (88.9) & \multirow{2}{*}{ _a } & $35(94.6)$ & 70 (90.9) & \multirow{2}{*}{0.755} \\
\hline Impact & $4(8.5)$ & - & $5(11.1)$ & & $2(5.4)$ & $7(9.1)$ & \\
\hline \multicolumn{8}{|l|}{ Handicap } \\
\hline No impact & $47(100.0)$ & $22(100.0)$ & $43(95.6)$ & \multirow{2}{*}{-a } & $37(100.0)$ & 75 (97.4) & \multirow{2}{*}{1.000} \\
\hline Impact & - & - & $2(4.4)$ & & - & $2(2.6)$ & \\
\hline
\end{tabular}

a Could not perform the test due to presenting cells with lower than the expected counts of 5 .

\section{Discussion}

The application of the OHIP-14 questionaire in this study showed that patients using prostheses present a satisfactory QoL. According to Slade ${ }^{14}$, this instrument presents $94 \%$ of concordance with OHIP-49, good reliability, validity and precision and requires less time for application, favoring its use during the evaluation of oral health and QoL.

Additional and recent studies also used the OHIP-14 version to evaluate QoL in individuals who used implant-supported prostheses ${ }^{1-2,5,11}$, as this test is proven to be a valid instrument that is reproducible, reliable and simple for use. Other studies have also reported the OHIP-14 to represent a good instrument for evaluation of QoL ${ }^{1,5,15-16}$

Despite these considerations, the cross-sectional evaluation used herein presents some limitations. For example, it is not possible to form any conclusions regarding the whole population with regard to improvements in QoL or evaluate cause-effect relationships between QoL and implant-supported prostheses use ${ }^{17}$. However, some authors have demonstrated a significant improvement in QoL when comparing before and after treatment with implant-supported prostheses ${ }^{1-2,5,11,15}$. This fact corroborates the low values found in this study. Other studies have reported the use of implants for prosthesis retention promotes a significant improvement in QoL and, if well planned, the treatment is able to decrease masticatory deficiency and psychological discomfort, in addition to providing aesthetic, retention and satisfactory stability ${ }^{18-19}$.

In this study, gender had an impact on the two parameters where women complained more about functional limitations and psychological discomfort. It is commonly considered that women are more interested in their appearance than men. This the higher dissatisfaction level for females could be related to the idea that the self-esteems of females could be affected from physical injuries more than males ${ }^{20-21}$. 
The perception of most negative may show women are more worried with their oral health when they evaluate their QoL ${ }^{13}$. According to Cohen-Carneiro et al. ${ }^{13}$, these differences in gender could vary according to sociodemographic characteristics. Due to the limited number of studies in the literature to explain these differences, it is difficult to justify or discuss these discrepancies in relation to gender.

Similarly to the results of the present study, other studies have not observed significant differences in relation to the time of use of prostheses, according to OHIP-145-6,22. Kouppala et al. ${ }^{2}$ also compared groups of patients for 3 to 12 years and 13 to 22 years of follow-up and did not find any statistical differences in the results for OHIP-14. Longitudinal evaluations of these patients are necessary to determine or confirm the high QoL over time.

Based on type of prosthesis, the present study did not show significant differences with regard to the type of prosthesis. However, Cakir et al. ${ }^{1}$ demonstrated that QoL values were lower in fixed partial prosthesis users and higher in overdenture-retained implant users, mainly due to functional limitations, physical incapacity and psychological discomfort dimensions. The authors justified an overdenture could represent a better improvement for an edentulous patient than a fixed-partial prostheses represents for a partially edentulous patient. These types of prostheses present advantages and disadvantages, although it remains difficult to define the best type of prosthesis categorically and its influence on QoL. These questions are also influenced by the technical knowledge of the professional, as well as social, systemic, financial and physical aspects of patients ${ }^{22}$.

Overdenture offers the patient an excellent ability to speak and chew ${ }^{23}$ and less mobility in the mouth than to conventional prostheses, and the cost over multiple prostheses or total prostheses (fixed) is an advantage for low-income individuals ${ }^{24-26}$. The advantages and the important factors for the choice of treatment with multiple prostheses or total prostheses (fixed) are the comfort and stability caused by the number of implants placed, such as that experienced with natural teeth ${ }^{23,26,27}$. Therefore, more research relating QoL and costs, considering the number of implants and the type of prosthesis, are necessary.

Some categories presented impact related to age analyzed, although no significance. The scientific literature showed that patients over 65 years were more satisfied with their implant-supported prostheses. This may be explained by the fact the elderly often experience edentulism and are satisfied with an oral health below that considered to be excellent, while younger patients with professional commitments have to deal with different contexts and social situations².

The results of this cross-sectional study indicate prosthetic rehabilitation with implants positively influences the QoL of patients, which could have both social impacts and benefits for daily activities. Additional studies that evaluate other sociodemographic information and patients' perception, beyond those commonly and routinely observed in rate success (biological and mechanical factors of rehabilitations), should be performed.

It can be concluded patients with implant-supported prostheses present a satisfactory QoL. However, increased attention should be given by professionals in relation to women's expectations, due to higher psychological discomfort and functional limitations. Therefore, the OHIP-14 used to evaluate the impact of rehabilitation with implants on oral health and the QoL of patients could be considered as an important auxiliary in planning and making clinical decisions. 


\section{Conflict of interest}

There is no acknowledgements and financial support by any institution to support research. Besides that, the authors declare that we do not have conflict of interest.

\section{References}

1. Cakir O, Kazancioglu KO, Celik G, Deger S, Ak G. Evaluation of the efficacy of mandibular conventional and implant prostheses in a group of turkish patients: a quality of life study. J Prosthodont. 2014 Jul;23(5):390-6. doi: 10.1111/jopr.12120.

2. Kuoppala R, Näpänkangas R, Raustia A. Quality of Life of Patients Treated With Implant-Supported Mandibular Overdentures Evaluated With the Oral Health Impact Profile (OHIP-14): a Survey of 58 Patients. J Oral Maxillofac Res. 2013 Jul 1;4(2):e4. doi: 10.5037/jomr.2013.4204.

3. Okoński P, Mierzwińska-Nastalska E, Janicka-Kostrzewa J. Implant supported dentures: an estimation of chewing efficiency. Gerodontology. 2011 Mar;28(1):58-61. doi: 10.1111/j.1741-2358.2009.00303.x

4. Cibirka RM, Razzoog M, Lang BR. Critical evaluation of patient responses to dental implant therapy. J Prosthet Dent. 1997 Dec;78(6):574-81

5. Goiato MC, Torcato LB, dos Santos DM, Moreno A, Falcon-Antenucci RM, Dekon SFC. Quality of life and satisfaction of patients wearing implant-supported fixed partial denture: a crosssectional survey of patients from Araçatuba city, Brazil. Clin Oral Impl Res. 2015 Jun;26(6):701-8. doi: $10.1111 /$ clr. 12372

6. World Organization Health. WHOQOL: measuring quality of life. Geneva: World Organization Health; 1997

7. Jansson $\mathrm{H}$, Wahlin $\mathrm{A}$, Johansson $\mathrm{V}$, Åkerman $\mathrm{S}$, Lundegren $\mathrm{N}$, Isberg $\mathrm{PE}$, et al. Impact of periodontal disease experience on oral health-related quality of life. J Periodontol. 2014 Mar;85(3):438-45. doi: 10.1902/jop.2013.130188.

8. Sischo L, Broder HL. Oral health-related quality of life: what, why, how, and future implications.. J Dent Res. 2011;90(11):1264-70. doi: 10.1177/0022034511399918.

9. Mcgrath CM, Bedi R. A national study of the importance of oral health to life quality to inform scales of oral health related quality of life. Qual Life Res. 2004 May;13(4):813-8.

10. Bramanti E, Matacena G, Cecchetti F, Arcuri C, Cicciù M. Oral health-related quality of life in partially edentulous patients before and after implant therapy: a 2-year longitudinal study. Oral Implantol (Rome). 2013 Oct;6(2):37-42.

11. Slade GD, Spencer AJ. Development and evaluation of the Oral Health Impact Profile. Community Dent Health 1994;11(1):3-11.

12. Cohen-Carneiro F, Souza-Santos R, Rebelo MAB. Quality of life related to oral health: contribution from social factors. Cienc Saude Colet. 2011;16 Supl 1:1007-15

13. Slade GD. Derivation and validation of a short-form oral health impact profile. Community Dent Oral Epidemiol. 1997 Aug;25(4):284-90.

14. Berretin-Felix G, Nary Filho H, Padovani CR, Machado WM. A longitudinal study of quality of life of elderly with mandibular implantsupported fixed prostheses. Clin Oral Impl Res. 2008 Jul;19(7):704-8. doi: 10.1111/j.1600-0501.2007.01451.x.

15. Preciado A, Del Río J, Lynch CD, Castillo-Oyagüe R. Impact of various screwed implant prostheses on oral health-related quality of life as measured with the QoLIP-10 and OHIP-14 scales: a cross-sectional study. J Dent. 2013 Dec;41(12):1196-207. doi: 10.1016/j.jdent.2013.08.026. 
16. Azevedo MS, Goettems ML, Torriani DD, Demarco FF. Factors associated with dental fluorosis in school children in southern Brazil: a cross-sectional study. Braz Oral Res. 2014;28(1):1-7. pii: S1806-83242014000100225.

17. Geckili O, Bilhan H, Mumcu E, Dayan C, Yabul A, Tuncer N. Comparison of patient satisfaction, quality of life, and bite force between elderly edentulous patients wearing mandibular two implantsupported overdentures and conventional complete dentures after 4 years. Spec Care Dentist. 2012 Jul-Aug;32(4):136-41. doi: 10.1111/j.1754-4505.2012.00258.x.

18. Thomason JM. The use of mandibular implant-retained overdentures improve patient satisfaction and quality of life. J Evid Based Dent Pract. 2010 Mar;10(1):61-3. doi: 10.1016/j.jebdp.2009.11.022.

19. Vallittu PK, Vallittu AS, Lassila VP. Dental aesthetics: a survey of attitudes in different groups of patients. J Dent 1996 Sep;24(5):335-8.

20. Strajnić L, Bulatović D, Stančić I, Živković R. Self-perception and satisfaction with dental appearance and aesthetics with respect to patients' age, gender, and level of education. Srp Arh Celok Lek. 2016;144(11-12):580-9.

21. Gates WD 3rd, Cooper LF, Sanders AE, Reside GJ, De Kok IJ. The effect of implant-supported removable partial dentures on oral health quality of life. Clin Oral Implants Res. 2014 Feb;25(2):207-13. doi: 10.1111/clr.12085.

22. Heydecke G, Boudrias P, Awad MA, De Albuquerque RF, Lund JP, Feine JS. Within subject comparisons of maxillary fixed and removable implant prostheses. Patient satisfaction and choice of prosthesis. Clin Oral Impl Res 2003 Feb;14(1):125-30.

23. Sadowsky SJ. The implant-supported prosthesis for the edentulous arch: design considerations. J Prost Dent 1997 Jul;78(1):28-33.

24. Kim Y, Park SY, Park JY, Jeong YJ, Kim J, Oh SH et al. Economic Evaluation of Dental Implants in Korea. Seoul, Korea: National Evidence-based healthcare Collaboration Agency; 2011.

25. Emami E, de Souza RF, Bernier J, Rompre P, Feine JS. Patient perceptions of the mandibular three-implant overdenture: a practice-based study. Clin Oral Implants Res. 2015 Jun;26(6):639-43. doi: $10.1111 /$ clr.12351.

26. Preciado A, Del Rio J, Lynch CD, Castillo-Oyague R. A new, short, specific questionnaire (QoLIP-10) for evaluating the oral health-related quality of life of implant-retained overdenture and hybrid prosthesis wearers. J Dent 2013;41:753-63. doi: 10.1016/j.jdent.2013.06.014. 